\title{
A personal vision: the future of solar energy and why it matters
}

\section{Abstract}

Through personal experience, this essay attempts to demonstrate how important for our civilization the rapid development of solar energy is and how this can bring profound and beneficial transformative societal changes in the context of climate change. A shortlist of related research topics is provided to stimulate further developments.
Volume I Issue I - 2017

\author{
Christian A Gueymard \\ Solar Consulting Services, USA
}

Correspondence: Christian A Gueymard, Solar Consulting Services, Colebrook, NH 03576, P.O. Box: 392, Florida's office, USA,Tel I-3864028949,

Email Chris@SolarConsultingServices.com

Received: June 02, 2017 | Published: June 16, 2017

\section{I had a dream}

I just turned 14 in August 1963 when Martin Luther King Jr. pronounced his famous speech known as "I have a dream". This had such a profound impact on the American society that things started to change for the better regarding racism and segregation laws. In hindsight, this is proof to me that expressing one's dream at the right time can have incredible transformative power. My own dream at the time, which, as a timid adolescent, I could not express much, was that better, cleaner energy sources should be developed for the benefit of mankind. A few years later, I embarked on a scientific path toward that goal, which made me witness all the ups and downs of solar energy applications and policies during the decades that followed. Fortunately, thousands of other scientists and industrialists did the same thing over the world, so that this dream is now becoming reality. Solar energy is everywhere, becoming mainstream, and displacing conventional and polluting sources of energy, like coal or nuclear. Who would have believed in such a dramatic and profound development just 15 or 20 years ago? At the time, even the most insightful scenarios, from e.g. the International Energy Agency (IEA), were far from projecting the monumental boom that actually happened since then. This profound transformation of the energy sector that followed so rapidly has even an important side effect on society too. For the first time since electricity started redefining our civilization some 120 years ago, people can now have the chance to produce their own electricity and be independent from the grid, if they so wish (and can pay for). Although, in industrialized countries, only a minority can currently make this become reality by literally building a small house in the woods, this has great potential significance in developing countries or tiny islands. Just as the cell phone technology has leapfrogged the conventional telephone land lines there, distributed solar systems can effectively leapfrog the conventional paradigm of the electric grid and its need for huge infrastructure investments. This is, in essence, "power to the people". But, just like Dr. King's speech of 1963, there is also intense resistance to change, which tends to slow down the pace of any fundamental societal transformation.

\section{Energy is power}

From a scientific perspective, energy and power are two differentalbeit related-concepts. From a political/societal perspective, though, energy is power. In the recent past, countries depending on natural gas for the heating needs of their people and for industrial production became at risk of having their regular supply curtailed by their foreign providers. This could have had catastrophic consequences for the world's economic stability, and could even have triggered local wars. In history, countries with large natural resources have always been at risk of invasion or colonization. Such risks have heightened since WWII because of the strategic importance of oil and gas reserves. Fortunately, solar energy is virtually everywhere and cannot be stolen. Or can it? In recent years, Desertec and Transgreen were ambitious projects developed in Europe to secure its future supply of "clean energy" using a network of solar power plants to be implanted in northern Africa. The produced electricity would have been transported by power lines to Europe. One of the reasons these projects were short lived is of a geopolitical nature: The countries harboring those power plants would have had some de facto control over the electricity produced and could have used it as a bargaining chip or to exert political pressure.

From a societal perspective, this demise of large transnational projects parallels the surprisingly fast decline of concentrating solar technologies, namely Concentrating Photovoltaics (CPV) and Concentrating Solar Power (CSP). In my view, the two apparently different trends just described are actually related, at least symbolically: the Centralization of Power-political in the first instance and technological in the second-is not favored by the masses anymore. Power to the people? Yes, an obvious trend exists in that direction, but of course this will not be an easy path because many entrenched political and financial interests will try to fight it as long as possible, for instance by denying the reality of climate change. In any case, an exceptional feature of solar PV is its scalability, which allows solutions at all levels and for all power needs, from a fraction of Watt for portable consumer applications to GW-scale industrial 
power plants. Whether one prefers a centralized or a decentralized energy system, solar PV is the appropriate tool.

Whereas CPV has basically disappeared from the radar screen, CSP is still afloat, but with much lesser ambitions than just five years ago. Its main appeal resides in the possibility of storing power in the form of heat, to make the electricity produced by CSP plants of quasi-base load value. However, considering the rapid technical progress, huge investments, and declining costs of many forms of energy storage (such as high-performance batteries), this advantage of CSP systems over conventional PV might not last long. PV will be the reigning solar giant for the fore seeable future. Whereas wind power has its advantages and is already a mature technology, the wind resource is not as omnipresent as that of solar. Even though the solar resource is not evenly distributed over this planet, any location has at least something. It is unlikely that a country would invade another one to benefit from just a little more sun. The downside of this advantage, though, is also the weakness of solar energy: its energy density is low and, moreover, highly variable. This means that large areas are needed to produce significant amounts of energy (heat or electricity) and to smooth out local fluctuations. In particular, the efficiency of solar cells is still low, which can be considered as the Achilles' heel of solar power.

\section{Our solar future}

The dream I had in 1963 is becoming reality. Am I satisfied? Am I ready to retire? Of course not! There are so many improvements to do on many fronts before my real goal actually happens: Clean, sustainable and affordable energy for everybody! I hope this view is shared by many scientists and people all around the world. The big question is, how can we collectively succeed in manifesting this new paradigm?

Actually, let us realize that we do not have the choice. Based on the International Panel on Climate Change (IPCC) findings (and, I would say, just common sense), we only have a few decades to resolve, or at least attenuate, the climate change issue. Failure is not an option since, otherwise, its dire consequences might constitute the largest menace that humanity has faced in eons. Next, humanity has also only a few decades to become sustainable before it has irreversibly consumed most of its physical resources, has disappeared under its own garbage and pollution, or has become too fragile to resist the new pandemics propagated by indirect climate change effects. Indeed, a profound societal transformation is needed to overcome all these issues.

Incidentally, one controversial counter-measure, called geoengineering, is seriously considered to mitigate climate change effects by injecting particulates into the high stratosphere, thus increasing the planetary albedo, and ultimately reducing the transmitted solar irradiance in an attempt to lower the planet's temperature. Various studies have already evaluated its possible impacts on climate, as well as on solar energy applications. Is not it a ridiculous contradiction that geoengineering would decrease the solar resource everywhere, and hence the chances for solar energy applications to rapidly displace the major cause of climate changecarbon emissions? The reader will certainly remember that, in a 2012 special report.

(Renewable Energy Sources and Climate Change Mitigation, http://www.ipcc.ch/report/srren/), the IPCC recommended to increase the use of solar energy to curb carbon emissions.

\section{Scientific and technological progress}

If I were the captain of the mother ship called Earth, I would now command "All hands on deck". Humanity needs the help from everybody-and most importantly from its most brilliant minds-to overcome the current dangers it faces now. In terms of scientific research and technological development, I hope that this new journal, as well as all other publications dedicated to renewable energy, will flourish with new ideas, concepts, and even revolutionary inventions. The "PV revolution" has occurred mainly because of the steep decrease in prices, which is ubiquitously depicted by the "learning curve". But other battles need to be won before our societies do exclusively use clean and renewable sources of energy in a sustainable way. In my view, the most critical goals will be to:

a. Increase the efficiency of solar cells, while decreasing their production cost. This is obviously on everybody's mind, and there are multiple avenues to explore here: Neutralize the negative impact of temperature on efficiency or make the extra heat useful, decrease optical and shading losses, develop lowcost multijunction cells, improve the effectiveness of bifacial panels and of module-level power electronics, as well as the reliability of smart tracking systems, explore the apparently endless possibilities offered by new materials (graphene, perovskite, nanomaterials, etc.), develop 3D printing processes to "paint" buildings, roads and cars with PV coatings.

b. Solve the soiling and degradation issues with simple, environmentally-friendly and cost-effective tools, particularly in desert environments. How frustrating it is that intense soiling and high temperatures decrease the efficiency of PV systems exactly where the solar resource is typically maximum!

c. Continue the rapid development of storage solutions providing high energy densities. I dream of an AAA-size battery able to store $1 \mathrm{kWh}$ of electricity!

d. Optimally combine solar power generation, power storage, and grid integration, to overcome the difficulties resulting from the high variability of the solar resource. Eventually, small "smart" grids could be the link toward the fulfillment of the famous "Think global, act local" motto, and thus a key decentralization step toward literally transferring "Power to the people".

e. Investigate new avenues for large-scale energy production in space. The idea is not new in itself, since it was pioneered by the late Peter Glaser (1923-2014) in the early 1970s, but it needs new solutions to overcome the problem of safely transporting this energy to the surface for its eventual use.

f. Develop new "artificial intelligence" and "data mining" techniques, as well as new instruments for the constant monitoring of solar radiation and solar power production. I want to risk a prediction here: low-cost, high-performance sky cameras will soon become ubiquitous and will be able to perform a myriad of tasks, currently fulfilled by expensive scientific instruments, such as radiometers. Better and more numerous space borne instruments dedicated to the observation of clouds, aerosols, climate change indicators, etc., will also be needed to improve our knowledge of everything related to the solar resource and its spatio-temporal variability.

g. Make the scientific world collaborate more with grassroots 
movements and other stakeholders or organizations that try to shape our energy future. The message that needs to be conveyed clearly to the public is that a $100 \%$ energetically sustainable society is both urgently needed and technologically possible. Among many possible positive outcomes, this achievement would favor world peace, create many interesting jobs, and have the potential of starting a new era of "green" technological development.

h. Obtain the collaboration of independent inventors. Even though most of them are not scientists, or are not even inclined to work with scientists, they may surprise us with radically new ideas and brilliantly practical ways to harness solar energy. After all, our AC-based electric system owe its very existence to a genius-namely Nikola Tesla-who was more an inventor than a scientist.

\section{Conclusion}

To conclude, I wish I can continue to be of help to young scientists and to the cause of fulfilling their dreams of a better and sustainable "solar society".

\section{Acknowledgments}

None.

\section{Conflicts of interest}

The author declares that there is no conflict of interest. 